\title{
Rompendo os muros escolares
}

\author{
Breaking the school walls
}

\begin{abstract}
Adriana Salete Loss
Doutora em Educação pela Pontifícia Universidade Católica do Rio Grande do Sul. Professora Associada da Universidade Federal da Fronteira Sul. Chapecó - SC - Brasil

adriloss@uffs.edu.br
\end{abstract}

\begin{abstract}
Resumo: O texto "Rompendo os muros escolares" tem como tema central a discussão dos processos educacionais escolares, a partir das visões mono, multi e intercultural, objetivando provocar a reflexão sobre as práticas pedagógicas monoculturais e hegemônicas e sobre a necessidade da construção da resistência pedagógica por meio da educação multi/intercultural. O estudo de caráter bibliográfico, tem como foco a abordagem intercultural de Candau (2000), e em outros teóricos que fundamentam o multiculturalismo e a interculturalidade. A partir das reflexões evidencia-se que o desafio da educação intercultural está em problematizar as práticas pedagógicas e curriculares, na perspectiva de processos educativos e formativos voltados para pluralidade cultural, para a presentificação das diferenças e para a inclusão social. A educação intercultural como meio de resistência às propostas pedagógicas hegemônicas.
\end{abstract}

Palavras-chave: Educação Monocultural. Multiculturalismo. Educação Intercultural. Escola.

Abstract: The text "Breaking the School Walls" has as its central theme the discussion of school educational processes, based on the mono, multi and intercultural visions, aiming to provoke reflection on monocultural and hegemonic pedagogical practices and on the need to build pedagogical resistance by through multi / intercultural education. The study of bibliographical character, focuses on the intercultural approach of Candau (2000), and on other theorists who base the multiculturalism and the interculturality. From the reflections, it is evident that the challenge of intercultural education is to problematize pedagogical and curricular practices, in the perspective of educational and formative processes aimed at cultural plurality, for the presentiment of differences and for social inclusion. Intercultural education as a means of resistance to hegemonic pedagogical proposals.

Keywords: Monocultural Education. Multiculturalism. Intercultural Education. School.

\section{Introdução}

A presença do multiculturalismo tem desafiado os processos educacionais escolares para a educação intercultural, na perspectiva de superação das práticas pedagógicas monoculturalistas, etnocêntricas e excludentes. Pois, a pedagogia monocultural torna-se responsável, num sentido metafórico, pela construção dos "muros escolares", dos muros da igualdade nas desigualdades, dos preconceitos, das discriminações, das supervalorizações de alguns conhecimentos em detrimento de outros, dos processos competitivos, classificatórios e excludentes e da violência. 
A escola entre seus muros se institui com o poder de tornar o heterogêneo em homogêneo e as diferenças em igualdades, por meio de um discurso hegemônico. O discurso hegemônico é responsável pela divisão das classes sociais, pelas diversas formas de violência e exclusão social. Nessa perspectiva, de acordo com Gramsci (1999), existe "hegemonia" quando uma classe dominante não só é capaz de obrigar a uma classe subordinada a conformar-se a seus interesses, senão que exerce uma "autoridade social total" sobre essas classes e a formação social em sua totalidade, quando as frações de classe dominante não só dominam, senão dirigem e conduzem.

Desse modo, a proposta da educação intercultural, numa sociedade contraditória e conflitiva protagonizada pelos conflitos estruturantes (de classe), impulsiona à reinvenção dos processos educacionais como força contra-hegemônica e de resistência, na ousadia de romper com os "muros hegemônicos".

A educação intercultural, na perspectiva de Candau (2008) que se aproxima do multiculturalismo crítico de McLaren (1997), é o foco de nossas reflexões para a superação do modelo pedagógico escolar monocultural. Assim, o texto discute a emergência do rompimento dos muros escolares para a abertura, acolhimento e reconhecimento da pluralidade cultural e das diferenças, a partir de apontamentos críticos acerca das características das visões mono, multi e intercultural.

\section{Processos educacionais escolares: Entre o mono, o multi e o intercultural}

Para os Estudos Culturais, a cultura é um território de produção de significados em que entram em disputa diferentes grupos sociais, em que se constitui o jogo do poder da linguagem, do discurso, da construção da (s) identidade (s) e da (s) diferença (as). De acordo com Silva (2000), a identidade e a diferença são criadas pelos atos de linguagem do mundo cultural e social, resultantes de um processo de produção simbólica e discursiva e estão em estreita conexão com as relações de poder. Assim, a cultura passa a ser considerada como conjunto de conhecimentos, experiências e vivências singulares e plurais, que ocorrem em espaços e tempos diferentes.

A cultura é, por outro lado, a base de um forte vínculo social que nos aproxima daqueles com quem partilhamos as representações do mundo, os traços culturais em geral e os modos de se comunicar, formando um todo 'nós cultural'. Em suma, a cultura proporciona-nos uma noção de 
'nós' como membros de um grupo social que tem uma dada trajetória histórica; dá-nos a consciência de sermos continuadores dos 'outros', mas semelhantes a nós. (SACRISTÁN, 2002, p. 127-128).

Pela cultura ou culturas, o aprender e o pensar emergem e, mediatizados pela linguagem, consequentemente, geram novas construções e reconstruções das experiências individuais e coletivas. Ou, ainda, é na interação com os outros que o ser humano descobrese construtor da realidade, em que ao usar as ferramentas de sua cultura, nos seus modos de pensamento, e ao dialogar com outras culturas, se vê diante de novas possibilidades para o ser, fazer, viver, conviver e se relacionar. Assim, Sacristán (2002, p. 61) afirma: "Se a maior parte da experiência humana que assumimos na nossa biografia está alimentada através da rede da nossa socialização com os outros, isso deve-se, em grande parte, à linguagem".

Desse modo, a subjetividade humana também participa na constituição da identidade cultural do sujeito individual e coletivo. Para McLaren e Giroux (2000):

Nossas subjetividades são construídas em linguagem através do jogo de discursos e das posições de sujeito que consentimos em assumir. Os discursos não podem ser entendidos fora dos padrões institucionais, das formas de transmissão, das práticas sociais e dos interesses materiais que os caracterizam e sustentam. [...]. (McLAREN; GIROUX, 2000, p. 37).

Ainda, para estes autores o uso da linguagem é partidário e político. Isto é, a conceituação que damos para diversidade cultural, por exemplo, é constituída pela concepção de sociedade e de homem e mulher que possuímos. Se nossa concepção é acrítica podemos dizer que o respeito à diversidade se caracteriza pela atitude da tolerância entre as pessoas, os povos e as culturas. Já, numa perspectiva crítica, a diversidade cultural tem como característica, o acolhimento, o diálogo e o reconhecimento das diferenças culturais, estas permeadas pela desigualdade e pelo conflito.

Nessa direção, passamos a refletir sobre os processos educacionais escolares nas visões monocultural, multicultural e intercultural, com base nos fundamentos de Fleuri (2001, p. 48):

De um lado, o monoculturalismo entende que todos os povos e grupos compartilham, em condições equivalentes, de uma cultura universal. A visão essencialista, universalista e igualitária do monoculturalismo corre, porém, o risco de legitimar a dominação de um projeto civilizatório, que exclua ou subjugue as minorias cultuais.

Do outro lado, o multiculturalismo reconhece que cada povo e cada grupo social desenvolve historicamente uma identidade e uma cultura próprias. Considera que cada cultura é válida em si mesma, na medida em que 
corresponde às necessidades e às opções de uma coletividade. Ao enfatizar a historicidade e o relativismo inerentes à construção das identidades culturais, o multiculturalismo permite pensar alternativas para as minorias. Mas também pode justificar a fragmentação ou a criação de guetos culturais, que reproduzem desigualdades e discriminações sociais.

\subsection{A visão monocultural}

O monuculturalismo, conforme Kincheloe e Steinberg (2012), é caracterizado pelos discursos do neocolonialismo, em que os brancos são superiores aos outros de diferente cor, pela supremacia do Homem Branco; pelos discursos de igualdade na desigualdade; e, os discursos de educação assimilacionista, em que todos precisam ter acesso a cultura comum.

Nesse sentido, a concepção do monoculturalismo contribuiu para a presentificação de uma educação escolar caracterizada como:

- espaço organizado para o encontro das gerações - a escola reúne para a transmissão do conhecimento de geração a geração, numa perspectiva educacional do consenso e do conservadorismo;

-espaço do culto à cultura única - a escola incumbe-se da reprodução do pensamento dos grupos culturais dominantes;

- espaço do mundo intelectual - a emoção, os sentimentos e a afetividade entre professor e

o estudante são evitados, e a ênfase é dada ao pensamento racional e científico;

- espaço do sacerdócio docente - o educador é um sujeito vocacionado para o trabalho, considerado o "iluminado" para testemunhar a verdade e os valores morais.

Assim, para Peres (2000, p. 281), temos o professor monocultural com um perfil que:

- Considera a diversidade cultural como um obstáculo e um déficit ao processo de ensino aprendizagem;

- Defende um curriculum fechado e homogêneo, veiculando uma cultura oficial para todos - o etnocentrismo.

- Promove a competição dos alunos, criando dispositivos de compensação (educação compensatória) para os mais "fracos"/grupos minoritários.

- Reconhece e compreende as diferenças sociais e culturais, porém, desenvolve um trabalho de "manutenção".

- Ignora as vivências/experiências dos alunos, desvalorizando a educação não formal e informal.

- Permanece nas tradições liberais e conservadoras, fomentando os ghettos da escola. 
Desse modo, temos uma proposta de educação bancária, da pedagogia acrítica. A escola como reprodutora do sistema capitalista, que inculca noções de disciplina, de tempo e de trabalho produtivo, conforme Enguita (1989). Metaforicamente, a escola capitalista é o espaço em que se aprende o trabalho alienado e subserviente.

A visão monocultural, nos processos educacionais escolares, é fundamentada na concepção filosófica essencialista, que tem como objetivo o desenvolvimento do homem racional, intelectual e moral. Também, tem seus fundamentos na sociologia funcionalista, em que o trabalho escolar é a preparação para o trabalho no mercado. Nessa perspectiva, a relação educativa constitui-se de forma linear e fragmentada, em que o poder é centralizado no professor, aquele que sabe e ensina o outro (o aluno) que não sabe. A obediência ao professor é a obediência ao "chefe" para o futuro emprego, se vier a conquistar.

Assim, na sociedade brasileira, da pluralidade cultural e das desigualdades, quem serão os serviçais? Quem serão os desempregados, os excluídos, os marginalizados, os discriminados? A estas indagações é fácil de responder: são os negros, os povos indígenas, os trabalhadores assalariados, os sem teto, os sem terra; todos que a política neoliberal os rouba de seus direitos de cidadania.

\subsection{A visão multi e intercultural}

A literatura sobre Educação multicultural surge no contexto dos países anglo-saxões, e temos nos Estados Unidos, dois importantes autores que abordam a questão do multiculturalismo que são Peter McLaren e James Banks.

Peter McLaren (apud,2012, Kincheloe e Steinberg), reconhece cinco tipos de multiculturalismo; são eles: a) O Multiculturalismo conservador ou monoculturalismo; b) O Multiculturalismo liberal; c) $\mathrm{O}$ Multiculturalismo pluralista; d) O Multiculturalismo Essencialista de Esquerda; e) O Multiculturalismo Teórico. Os quatro primeiros tipos são voltados à concepção hegemônica de sociedade, acrítica aos processos educativos escolares, enquanto o último tipo se apresenta como perspectiva contra-hegemônica e crítica.

De acordo com Sabariego (2002), no contexto europeu existe um consenso geral dos autores que reconhecem o termo intercultural com a conotação diferente do multicultural.

O termo multicultural expressa simplesmente a situação real de uma sociedade com vários grupos culturais que mantêm uma certa coesão entre si a partir de alguns valores e normas. Enquanto o termo intercultural 
afirma explicitamente a realidade do diálogo, a reciprocidade, a interdependência e expressa um desejo, um método de intervenção por meio do qual a interação entre as diferentes culturas seja uma fonte de enriquecimento mútuo. (SABARIEGO, 2002, p. 74).

Assim, a interculturalidade reconhece as diferenças na diversidade cultural e constitui abertura para o etnoconhecimento e o etnosaber. A educação intercultural busca,

[...] reconhecer e valorizar as expressões culturais particulares de todos os agrupamentos humanos, não só por uma razão epistemológica, evitando assim todas as formas de etnocídio epistêmico, mas também por razões éticas e políticas, pois sem a garantia de sua identidade, as pessoas humanas não podem ser autônomas, livres e emancipadas. (SEVERINO, 2013, p. 42).

Desse modo, a educação escolar, na perspectiva da educação intercultural, se apresenta como espaço de culturas antagônicas, em que a diversidade está presentificada no individual e no coletivo. A relação intercultural emerge da singularidade e da pluralidade de concepções, ideias, valores, costumes, crenças, etc, constituindo-se na reciprocidade e no conflito. Ainda, em espaço da autonomia dos sujeitos, em que o educador compreende o educando como um ser de liberdade, ou seja, na relação educativa há a descentralização do poder, em que o diálogo problematiza as experiências culturais.

Para Sabariego (2002) educação intercultural, admite que a diversidade étnica e cultural é um elemento positivo e enriquecedor na vida de todas as pessoas e que pretendem contribuir para o educando no reconhecimento e aceitação tanto da própria identidade como reconhecer as identidades culturais dos outros.

Conforme Peres (2000), o professor/educador intercultural, tem atitudes práticoreflexivas e críticas; defende um curriculum aberto e flexível, adaptado aos contextos multiculturais; promove o diálogo e a colaboração (pedagogia interativa) com os grupos minoritários e com os grupos maioritários, defendendo um projeto social; defende a emancipação cultural e a reconstrução social; estimula a educação não formal e informal, estabelecendo pontes entre experiências anteriores à escola e os projetos curriculares; concilia a tradição com a inovação, revisitando cada vez mais os momentos mais significativos da cultura comunitária; e, defende a descentralidade da escola, em que essa instituição faz parte da comunidade.

Nessa perspectiva, Candau e Koff (2006, 489-490), pontuam alguns desafios a serem enfrentados pelos educadores para a promoção da Educação Intercultural: 
- Penetrar no universo de preconceitos e discriminações presentes na sociedade brasileira. Essa realidade se apresenta entre nós com um caráter difuso, fluído, muitas vezes sutil, e está presente em todas as relações sociais. A "naturalização" é um componente que a faz em grande parte invisível e especialmente complexa. Para a promoção de uma educação intercultural é necessário reconhecer o caráter desigual, discriminador e racista da nossa sociedade, da educação e de cada um (a) de nós. Desenvolver estratégias nessa perspectiva é fundamental.

- Questionar o caráter monocultural e o etnocentrismo que explícita ou implicitamente impregnam os currículos escolares. [...].

- Articular igualdade e diferença: é importante articular no nível das políticas educativas, assim, como das práticas pedagógicas, o reconhecimento e a valorização da diversidade cultural, com as questões relativas à igualdade e ao direito à educação, como direito de todos (as).

- Resgatar os processos de construção das nossas identidades culturais, tanto no nível pessoal como no coletivo. As histórias de vida e da construção de diferentes comunidades socioculturais são elementos fundamentais nessa perspectiva. [..].

- Promover experiências de interação sistemática com os "outros": para sermos capazes de relativizar nossa própria maneira de situarmo-nos diante do mundo e atribuir-lhe sentido, é necessário que experimentemos uma intensa interação com diferentes modos de viver e expressar-se. [...]. - Reconstruir a dinâmica educacional: a educação intercultural não pode ser reduzida a algumas situações e/ou atividades realizadas em momentos específicos, nem focalizar sua atenção exclusivamente em determinados grupos sociais. Trata-se de um enfoque global, que deve afetar todos os atores e a todas dimensões do processo educativo, assim como os diferentes âmbitos em que ele se desenvolve. No que diz respeito à escola, afeta a seleção curricular, a organização escolar, as linguagens, as práticas didáticas, as atividades extraclasse, o papel do professor, a relação com a comunidade etc.

- Favorecer processos de "empoderamento", principalmente orientados aos atores sociais que historicamente tiveram menos poder na sociedade, ou seja, menores possibilidades de influir nas decisões e nos processos coletivos. O "empoderamento" começa por liberar a possibilidade, o poder, a potência que cada pessoa tem, para que ela possa ser sujeito de sua vida e ator social. [...].

Assim, nos processos educacionais escolares, na perspectiva da educação intercultural, há o respeito, o acolhimento e o reconhecimentos dos diferentes saberes e inteligências. A pluralidade cultural, os processos de discriminação, as diferenças culturais, os preconceitos, as classes sociais, entre outros, são conteúdos emergentes para o diálogo crítico, na constituição da igualdade de direitos.

Nesse sentido, a educação multi/intercultural requer um processo pedagógico de mediação dos conflitos, em que aos sujeitos é facultada a liberdade para o diálogo, de modo a permitir a não cegueira frente ao mundo do Eu e do Nós. Assim, conforme Fontoura (2005, p. 56), "Optar pela interculturalidade significa optar por um tipo de sociedade que 
aposta na integração das diferenças. Integrar pressupõe dar a cada um, ao longo de toda a vida, a capacidade de participar ativamente no projeto de sociedade”.

\section{Considerações finais}

Os processos educativos e formativos, na perspectiva da educação intercultural, requerem uma relação educativa que instigue a socialização de experiências entre as diferentes gerações e culturas, permeada pela metodologia do conflito e da transformação. Isso significa, promover "uma relação de troca e de reciprocidade entre pessoas vivas, com rostos e nomes próprios, reconhecendo reciprocamente seus direitos e sua dignidade. Uma relação que vai além da dimensão individual dos sujeitos e envolve suas respectivas identidades culturais diferentes" (FLEURI, 2001, p.53).

Nesse sentido, a proposta da educação multi e intercultural necessita constituir espaços educativos promotores da participação, da sensibilização, da autonomia, da capacidade crítica e da ação interventiva no contexto social, pois conforme Peres (2000, p. 121):

A escola deve definir-se, cada vez mais, como um lugar de encontro, diálogo, afeto, convivência, onde todos e cada um se sintam bem e possam participar e intervir em atividades instrutivas/educativas, interessantes e estimulantes, independentemente das diferenças de raça, etnia, sexo, idade, religião, língua, cultura - uma escola aberta à negociação e à diversidade cultural, ou seja, uma escola multi-intercultural.

Assim, na perspectiva do autor a escola precisa se definir como espaço em que os sujeitos se sintam reconhecidos, incluídos e protagonistas, no sentido da cidadania intercultural.

Para tanto, é fundamental que haja a problematização das nossas concepções de ciência, de conhecimento, de educação, de escola e de cultura, para compreendermos a natureza das relações entre a cultura escolar, a cultura da escola e a cultura social, conforme Candau (2000). Também, é necessário que a escola possa romper com seus muros atentandose para o que afirma Rancière (2002, pl 25): “[...] Há embrutecimento quando uma inteligência é subordinada a outra inteligência. Ainda, ele afirma: [...] Para emancipar um ignorante, é preciso e suficiente que sejamos, nós mesmos, emancipados; isso é, conscientes do verdadeiro poder do espírito humano (2002, p. 27)”. 


\section{Referências}

CANDAU, Vera Maria; KOFF, Adélia Maria Nehme Simão e. Conversas com... sobre a Didática e a Perspectiva Multi/Intercultural. Revista Ciências da Educação - Educação \&o Sociedade, Campinas, v. 27, maio/ago. 2006.

CANDAU, Vera Maria (Org.). Reinventar a escola. Petrópolis: Vozes, 2000.

Direitos humanos, educação e interculturalidade: as tensões entre igualdade e diferença. Revista Brasileira de Educação, v. 13, n. 37, jan./abr. 2008. Disponível em: < http://www.scielo.br/pdf/rbedu/v13n37/05.pdf. >. Acesso em: 06 jun. 2018.

ENGUITA, Mariano Fernández. A face oculta na escola: educação e trabalho na escola. Porto Alegre: Artes Médicas, 1989.

FLEURI, Reinaldo Matias. Desafios à educação intercultural no Brasil. Revista PerCursos. v. 2, n. $0 . \quad$ FLORIANÓPOLIS, 2001. Disponível em: $<$ http://www.periodicos.udesc.br/index.php/percursos/issue/view/169>. Acesso em: 06 jun. 2018.

FONTOURA, Madalena. Uns e outros: da educação multicultural à construção da cidadania. Educa: Lisboa, 2005.

GRAMSCI. Cadernos do Cárcere. Rio de Janeiro: Civilização Brasileira, 1999.

HARPER, Babette; CECCON, Claudius; OLIVEIRA, Miguel Darcy de; OLIVEIRA Rosiska Darcy de. Cuidado Escola! São Paulo: Brasiliense, 2006.

KINCHELOE, Joe L.; STEINBERG Shirley R. Repensar el multiculturalismo. Barcelona: Ediciones Octaedro, 2012.

McLAREN, Peter. Multiculturalismo crítico. São Paulo: Cortez, 1997.

; GIROUX, Henry. Escrevendo das margens: geografias de identidade, pedagogia e poder. 2000. In: McLAREN, Peter. Multiculturalismo revolucionário - pedagogia do dissenso para o novo milênio. Porto Alegre: ARTmed, 2000. p. 25 a 49. 
PERES, Américo Nunes. Educação Intercultural - Utopia ou realidade? - Processos de pensamento de professores face à diversidade cultural: integração de minorias migrantes na escola (Genebra e Chaves). 2. ed. Porto: Profedições, 2000.

RANCIÉRE, Jacques. O mestre ignorante: cinco lições sobre emancipação intelectual. Belo Horizonte: Autêntica, 2002.

SABARIEGO, Marta. La Educación intercultural - ante los retos del siglo XXI. Espanha: DESCLÉE, 2002.

SACRISTÁN, Gimeno J. Educar e conviver na cultura global. Porto/Portugal: ASA, 2002.

SEVERINO, A. J. Interculturalidade, educação e encontro de pessoas e povos. In: CARVALHO, A. D. (Org.). Interculturalidade, educação e encontro de pessoas. Porto: Edições Afrontamento, 2013.

SILVA, T. T. da. (Org.). Identidade e diferença: a perspectiva dos estudos culturais. Petrópolis, Rio de Janeiro: Vozes, 2000.

recebido em 06 jun. 2018 / aprovado em 22 nov. 2018

Para referenciar este texto:

LOSS, A. S. Rompendo os muros escolares. Dialogia, São Paulo, n. 30, p. 147-156, set. /dez. 2018. Disponível em: < https://doi.org/10.5585/Dialogia.n30.8774> 